\title{
Editorial
}

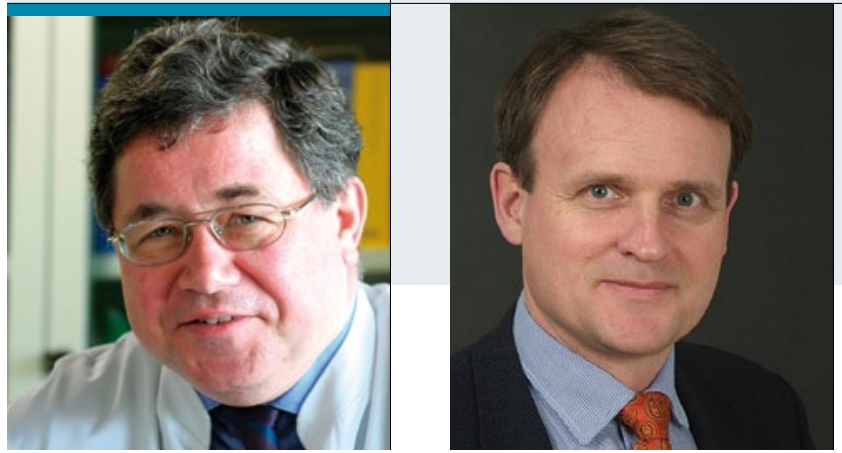

„Auf Basis einer umfangreichen Daten-

grundlage hat Prof. Dr. Jürgen Wasem eine

erhebliche Unterversorgung von Allergikern in

Deutschland belegen können."

Prof. Dr. Hans F. Merk, Hautklinik der Medizinischen Fakultät, Universitätsklinikum der RWTH Aachen Prof. Dr. Thilo Jakob, Allergieabteilung \& Forschergruppe Allergologie, Klinik für Dermatologie \& Venerologie, Universitätsklinikum Freiburg

\section{Therapiemöglichkeiten gut, Versorgungssituation schlecht}

D iese Ausgabe des Allergo Journal erscheint zum 8. Deutschen Allergiekongress und beinhaltet ab S. 382 die Kongressabstracts. Darüber hinaus erscheint in dieser Ausgabe ab S. 366 eine Originalarbeit, in der wichtige Daten von über 40 Millionen Versicherten der gesetzlichen Krankenkassen zur Versorgung der Allergiker in Deutschland analysiert wurden (vgl. Allergo J 2012; 21: 516). Im Auftrag des Ärzteverbands Deutscher Allergologen (AeDA) hat der Essener Gesundheitsökonom Prof. Dr. Jürgen Wasem auf Basis dieser umfangreichen Datengrundlage eine erhebliche Unterversorgung von an Allergien erkrankten Patienten in Deutschland belegen können. Damit stehen die Daten jetzt auch für eine internationale Diskussion zur Verfügung. In weiteren Untersuchungen wird es gelten, die Konsequenzen für Patienten und Gesundheitssystem, die durch diese Unterversorgung entstehen könnten, zu beschreiben. Aspekte der Unterversorgung von Patienten mit allergologischen Erkrankungen wie der allergischen Rhinitis werden auch im CME-Beitrag von Prof. Dr. Ralph Mösges und Mitarbeitern angesprochen (S. 374).
Die Diskrepanz zwischen der Versorgung von Allergikern und den Möglichkeiten, die die moderne Immunologie und Pharmakologie gerade bei diesen Krankheitsbildern bieten, werden beim Lesen der Abstracts zum 8. Allergiekongress in Bochum offensichtlich. Das gesamte Spektrum moderner Allergologie in Diagnostik und Therapie einschließlich den Fortschritten bei der spezifischen Immuntherapie und einer komponentenbasierten Diagnostik werden hier dargestellt.

Die Serie „Das kleine 1 x 1 der Immunologie“ wird in diesem Heft mit dem Thema „Antimikrobielle Peptide und Protein" von Prof. Dr. Jens M. Schröder fortgesetzt (S. 362).

Wir wünschen allen Lesern des Allergo Journal eine spannende Lektüre und einen interessanten und abwechslungsreichen Besuch des 8. Deutschen Allergiekongresses in Bochum.

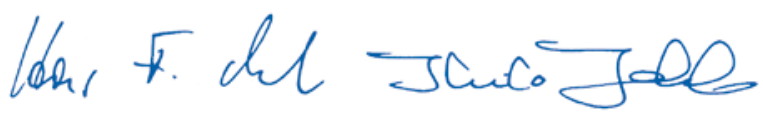

